\title{
Aging well with friends and family
}

\section{By: Rebecca G. Adams and Rosemary Blieszner}

Adams, Rebecca G., and Rosemary Blieszner. "Aging well with friends and family." American Behavioral Scientist 39.n2 (Nov-Dec 1995): 209(16).

Made available courtesy of SAGE Publications: http://abs.sagepub.com/ $* * *$ Note: Figures may be missing from this format of the document

\begin{abstract}
:
Aging encourages people to enhance their friend and family relationships. In general, the elderly tend to have more heterogeneity in relationships as they grow older. They depend on these relationships for instrumental, financial and emotional support. As a result, older adults who have many friends and have close ties with their families are more socially and psychologically well-adjusted than those who are alienated from their networks.
\end{abstract}

\section{Article:}

An assumption runs throughout the gerontological literature that having friends and active relationships with family members is better than not having them. Since the 1960s, when social gerontologists began debating the relative merits of the disengagement and activity theories, researchers have used the number of friends, the existence of active family relationships, and the amount of contact older adults have with these presumed intimates as indicators of aging well. Recently, however, researchers have recognized that not all personal relationships are good ones and not all social interactions affect older adults positively (e.g., Rook, 1984, 1989). In considering the connection between personal relationships and aging well, it is thus necessary to deconstruct friendship and kin relationships, to examine their myriad dimensions, and to recognize that merely having relationships is not an indication that someone is aging well.

The tendency of researchers to assume that all personal relationships are positive is not the only limitation characteristic of the investigations on this topic. In both the family and friendship literatures, samples are often less than adequate, either being representative of very specific subpopulations of older adults or not being representative of any population at all (i.e., snowball, volunteer, or other nonprobability samples). Personal relationship researchers tend to study single respondents rather than pairs of friends or family members. When they do investigate dyads, they often study them in isolation rather than considering them in the context of the family or friendship network. Both literatures are also primarily descriptive rather than theoretically motivated, and, consequently, what is known about relationships is little more than a list of findings of all studies.

Each of these personal relationship literatures has additional limitations. For example, researchers have rarely studied friendships longitudinally, making it impossible to examine changes in friendship as people age and to separate out age, period, and cohort effects. Gerontological friendship researchers usually study single-race (almost always Caucasian) or single-sex (usually female) populations; when they do include more than one race or both 
genders, they rarely compare and contrast them. Perhaps because of the ambiguous meaning of friendship in American culture, researchers have defined it in myriad ways, making comparisons across studies or general summaries of findings. difficult (see Adams, 1989, for a discussion of the variety of ways in which researchers have operationalized the concept friend).

Similarly, family gerontologists have favored cross-sectional over longitudinal designs and have usually focused on Caucasian samples (but see Johnson, 1995, for a review of research on cultural diversity in late-life families). Moreover, they have often adopted a unidirectional stance in assessing family interaction patterns, apparently assuming that older members are only the recipients of support and care, to the neglect of research on the contributions of elders to family well-being. Thus investigators have focused unduly on the burdens of care giving by younger family members to older and have focused insufficiently on either the benefits of care giving or family dynamics when elders do not need extensive care. Many conceptualizations of family processes have been linear, when the reality of experience suggests that they encompass complex patterns of interaction (Blieszner \& Bedford, 1995a).

Although much research remains to be done before achieving full understanding of the impact of personal relationships on how well people age, nonetheless the literature contains more information than it did even a decade ago. Many gerontology textbooks now include discussions of friendship (e.g., Atchley, 1994; Cavanaugh, 1993; Manheimer, 1995); scholars have recently published several volumes including syntheses of the older adult friendship literature (e.g., Adams \& Blieszner, 1989; Allan, 1989; Blieszner \& Adams, 1992; O'Connor, 1992; Rawlins, 1992); and the number of articles focusing on older adult friendship in refereed journals has greatly increased. Likewise, compilations of the family gerontology literature have appeared in text and reference book form (e.g., Bengtson \& Achenbaum, 1993; Blieszner \& Bedford, 1995b; Brubaker, 1990a) and reports on family and aging issues have proliferated in family studies, gerontology, and other types of journals.

In this article, we begin by examining key dimensions of friend and family relationships and predictors of outcomes on each dimension. This information provides the background context within which elderly people make choices about relationships that contribute to or detract from aging well. Next, we discuss the contributions personal relationships can make to the everyday quality of life and the psychological well-being of older adults. Finally, we end with an analysis of policy issues regarding relationship interventions.

\section{DIMENSIONS OF PERSONAL RELATIONSHIPS}

Personal relationships consist of both structure and processes (see Adams \& Blieszner, 1994, and Blieszner \& Adams, 1992, for in-depth discussions of these elements). Structure is the form of ties linking an individual's relationships such as the number of associates, the hierarchy among them, the similarity of their social positions, the proportion of associates who know one another, and the amount of solidarity among them. Processes are the thoughts, feelings, and behaviors involved in relationships.

The mere existence of relationships does not indicate that older adults are aging well; more important are the structural and dynamic aspects of the relationships. Furthermore, no one constellation of characteristics of personal relationships is optimal for people as they age. Rather, 
depending on the situation facing them, older adults find specific characteristics of relationships helpful or detrimental. For example, having a homogeneous social network encourages intimacy, but the members of a heterogeneous social network have a wider variety of skills and resources to use in supporting an older adult. Similarly, in the event of an injury or illness, older adults whose friends and family members all know one another can instigate the organization of a support network with one telephone call. In contrast, older adults whose family members and friends are not in contact with one another can confide in an intimate without fearing the spread of gossip. As these examples show, different choices related to friend and family relationships (for example, cultivating a homogeneous versus a heterogeneous network) can either enhance or inhibit aging well, depending on aged adults' needs and abilities. In the next section, then, rather than prescribing the types of relationship choices that older adults should make to age well, we summarize research on dimensions of the personal relationships of older adults and on predictors of each of these characteristics. For both friends and family, we organize the review according to structural and process aspects of relationships.

\section{FRIENDSHIP}

\section{STRUCTURE}

Network size. The number of friends older adults have varies greatly depending on the circumstances facing them. For example, nursing home residents have fewer friends (Retsinas \& Garrity, 1985) than those dwelling in the community (Adams, 1987a). Looking at these two living situations more closely reveals additional variables that affect number of friends. In a nursing home, greater lucidity and better vision and speech are associated with having more friends (Retsinas \& Garrity, 1985). Among community-dwelling older adults, elderly women have more friends than do elderly men (Fischer \& Oliker, 1983), women in age-segregated housing have more friends than do those living elsewhere (Adams, 1983), employed women have more friends than do other older women (Babchuk \& Anderson, 1989), and participants in social activities have more friends than do nonparticipants (Spakes, 1979). Older widows have fewer friends than younger ones, but the number of married women's friends does not differ by age (Babchuk \& Anderson, 1989). Very old people have fewer casual friends than do those between the ages of 70 and 84 years, but not fewer close friends (Lang \& Carstensen, 1994).

Heterogeneity versus homogeneity. Older adults tend to have networks heterogeneous in terms of age, marital status, and education, but homogeneous in terms of sex and race (Usui, 1984). Older men and women are equally likely to have friends of different races, different ages, and with different levels of education in their networks (Usui, 1984; Weiss \& Lowenthal, 1975). Compared to older women, both older Black and Caucasian men have networks higher in marital status homogeneity and lower in sex homogeneity (Dykstra, 1990; Usui, 1984). The friendship networks of older Blacks are less homogeneous than their Caucasian counterparts in marital status. Unmarried elderly people have networks more heterogeneous in marital status than married elderly do. The older that people are, the more age heterogeneity characterizes their networks. The more educated that older adults are, the less educational heterogeneity characterizes their networks (Usui, 1984).

Network density. A higher proportion of the friends of older adults know one another in nursing homes than in age-segregated housing, and a higher proportion know one another in agesegregated housing than elsewhere in the community (Adams, 1983; Bear, 1990). In age- 
integrated settings, the friends of women with physically limiting conditions are less likely to know one another, whereas in age-segregated settings, the friends of such women are more likely to know one another (Adams, 1983).

\section{PROCESSES}

Cognitive. Research on how elderly people conceptualize friendship indicates that older women's and men's perceptions of important attributes of friendship do not differ significantly (Albert \& Moss, 1990). Across both men and women, some elders define friendship in terms of individuals who possess certain characteristics and thus are considered to be friends, whereas others focus on friendship as a relationship for which many different people might qualify (Matthews, 1983). Examination of solidarity, or perceived emotional closeness, among older women revealed that they differentiated among close friends, casual friends, and acquaintances on subjective indicators of relationship quality (satisfaction, emotional closeness, and the like) and acquaintances on various indicators of perceived relationship quality (Blieszner, 1993). According to Adams (1985), older women were unlikely to have cross-sex friendships because they held the belief that cross-sex friendships are preludes to romance, and they cited strong norms against courtship among older adults.

Affective. Older adults report high levels of enjoyment (Dykstra, 1990) and satisfaction (Adams, 1983) with their friends. Indicators of contentment with best friendships are general satisfaction, closeness, and appropriate levels of self-disclosure and emotional support (Jones \& Vaughan, 1990). Rook (1987) also found that reciprocity of exchanges, more evident in respondents' interactions with friends than with adult children, was significantly related to satisfaction with friend but not with family relationships. Negative feelings, too, can occur in friend relationships. For example, Fisher, Reid, and Melendez (1989) found that causes of anger with friends included irritation at those who failed to live up to role expectations for older adults (i.e., aging well) and envy over financial matters, health, physical attractiveness, and social relationships.

Behavioral. Cross-sectional research indicates that older women engage in different activities, such as social engagements and resource exchanges, with friends of differing levels of emotional closeness (Blieszner, 1993). Longitudinal studies show that contacts with friends tend to decline as people grow older (Hatch \& Bulcroft, 1992), with older women appearing better able to make and keep friends than older men are (Hatch \& Bulcroft, 1992; Matt \& Dean, 1993). Nevertheless, the majority of older adults have at least one close friend with whom they are in frequent contact (Johnson \& Troll, 1994), and some older adults have more friends than they did during the middle years (Adams, 1987a).

Affection and social support are displayed differently in new and long-standing friendships. Relationships with old friends are less dependent on overt exchanges of affection than are those with new friends and are more typically characterized as stable rather than fluctuating in the exchange of support (Shea, Thompson, \& Blieszner, 1988).

Friends serve as companions for each other in a variety of ways, such as sharing meals, conversations about everyday events, and joint activities (Dykstra, 1990). They also act as confidants, especially when no family members are available to fill that role (Connidis \& Davies, 1990). In addition to these beneficial functions, problems can occur in friendships. Hansson, 
Jones, and Fletcher (1990) noted that social networks can be sources of mixed motives, competition for scarce resources, plotting, deception, and violations of trust.

\section{IMPLICATIONS FOR AGING WELL}

Although friendships are conceptualized as voluntary relationships, they are not totally within the control of older adult participants. Not only do the other people involved in friendships shape them, but so do the situations in which older adults find themselves. Friendship options are different for men and women, the healthy and the frail, the poor and the rich, and so forth. As situations differ, so do emotional and instrumental needs. Not only do options differ, but so do preferences. Aging well is most likely to occur when people can take advantage of all the possibilities available to them. More research is needed on how contextual forces and personality affect the types of choices older adults make regarding their friendships.

\section{FAMILY RELATIONSHIPS}

\section{STRUCTURE}

Family size and generational composition. Demographic trends involving increased longevity, decreased fertility, and a high divorce rate have prompted gerontologists to predict the emergence of beanpole families in which four or five generations are alive simultaneously, but each generation comprises fewer members than in the past. Racial differences in longevity and in reproductive patterns (early versus delayed childbirth, matrilineal households) also affect the family structure of older adults (Bengtson, Rosenthal, \& Burton, 1990; Brubaker, 1990b). These trends, along with increased geographic mobility and the increased propensity of women to participate in the labor force, have important implications for family interaction patterns. Further, they imply that aging individuals, particularly women, spend much more time participating in various family roles and relationships than was the case previously.

Marital and parenthood status. Given that spouses and adult children, particularly daughters, provide most of the care that elderly persons receive, it is important to examine the availability of such potential helpers in American families. Although the majority of adults marry and have children, by old age these role statuses are less common, with differences noted according to sex and race. For adults aged 85 years and older, $53 \%$ of White men and $45 \%$ of Black men, but only $13 \%$ of White women and $11 \%$ of Black women, are married. In turn, again focusing on the oldest old, $81 \%$ of White men, $70 \%$ of Black men, $78 \%$ of White women, and $66 \%$ of Black women have at least one child living (Himes, 1992).

Household size and living arrangements. Trends toward lowered fertility and increased geographic mobility have also led to smaller households, more elders living alone, and more dispersed family networks. Black and Hispanic elders are more likely than White ones to live with nonspouse relatives (24\% and $26 \%$ compared with $12 \%$, respectively) (U.S. Bureau of the Census, 1990). The likelihood of living alone is associated with widowhood and thus increases with age and is more common for women. It is also more likely for those who were never married, those with higher incomes, and those enjoying better health, although decrements in functional capacity do not necessarily lead to shared dwelling (Kinsella, 1995; Worobey \& Angel, 1990). Nevertheless, living arrangements need not limit family interaction patterns; reciprocal support between generations of the family is not affected by lack of coresidence (Mancini \& Blieszner, 1989). 


\section{PROCESSES}

Cognitive. Several examples of research on the operation of cognitive processes within late-life family relationships, including sibling, parent-child, and grandparent-grandchild relations, are available. For example, because siblings share a family history, their relationships can serve to validate reminiscences of earlier' family experiences (Bedford, 1995; Brubaker, 1990b). With respect to parent-child relations, older adults' perceptions of their competence in the parenting role (Mancini \& Blieszner, 1989) and their assessments of their children's success with developmental challenges (Ryff, Schmutte, \& Lee, in press) affect their self-concept. Filial responsibility norms, which vary across generations in the family (Mancini \& Blieszner, 1989), guide the expectations that older adults. hold for receipt of support from their children (Blieszner \& Hamon, 1992). These norms, as well as degree of consensus on other beliefs and values in the family, evidence heterogeneity across gender, generation in the family, and racial ethnic: group (Bengtson et al., 1990). Also, memories of family problems from earlier years can affect the quality of relationships between adult children and their parents later on (Webster \& Herzog, 1995). Finally, the role of grandparent appears to be more salient for women than for men. In many families, grandparents represent stability and continuity in family rituals and values (Bengtson et al., 1990; Brubaker, 1990b).

Affective. Examples of affective processes in the literature pertain to spouse, sibling, and parentchild relations. The majority of older adults evaluate their marriages as happy or very happy, and marital adjustment seems to be stable over time in enduring relationships (Huyck, 1995). Marital satisfaction can be affected either positively or negatively by relationships with children (Huyck, 1995), provision of care to an ill spouse (Brubaker, 1990b), and the timing of retirement of each partner (Szinovacz \& Ekerdt, 1995). Longitudinal research has shown that over time, husbands report greater marital happiness and more affection than wives do, perhaps because the men are proud of their survivorship and accomplishments (Field, Minkler, Falk, \& Leino, 1993), In general, adults feel positive about their sibling relationships, with gender (females higher than males) and race (Black people higher than White) affecting feelings of intimacy, congeniality, and loyalty (Bedford, 1995). Aged parents enjoy feeling loved and needed by their children whom they continue to love over the years, although feelings of frustration can also occur in the parent-child relationship (Mancini \& Blieszner, 1989).

Behavioral. Investigations of behavioral processes in family life have focused on variables such as amount of contact, instrumental and emotional support received, and intergenerational transfers from older to younger family members. According to analyses of longitudinal data by Field and colleagues (1993), the importance of health status increases and the importance of socio-economic status decreases in explaining variance in number of contacts between old people and their family members. Contrary to their expectations, better health rather than poorer health was associated with more contacts, probably because the minority whose health declined sharply experienced unwanted dependency and relationship dissatisfaction. Field and associates (1993) also found that women, serving as family kin keepers, had more contact with relatives than men did, and their results suggested that widowed people had more family contact than married ones. 
Family members display their affection for and sense of obligation toward their elders by providing numerous forms of instrumental and emotional support (see the following sections). Variations in the type and amount of support given occur with respect to gender, age, marital status, and health of recipient (women, older persons, widowed persons, and those in poorer health receive more help than others); gender of provider (women in the family provide more help than men); family role (spouses provide the most assistance, followed by daughters); and racial ethnic group (Black family members give more aid than those in other groups) (Bengtson et al., 1990; Coward, Horne, \& Dwyer, 1992).

Older adults are not only the recipients of assistance from family members, however. In fact, many of them are primarily donors of money and emotional sustenance to members of younger generations in the family, with variation in patterns of assistance observed according to gender, race, and socioeconomic status (Bengtson et al., 1990). They also choose to remain actively involved in family relations by helping the extended family network maintain contact and emotional closeness between its members and by providing child care (Robertson, 1995).

\section{IMPLICATIONS FOR AGING WELL}

Family members can contribute to older adults' ability to age well by providing opportunities for them to contribute to the care and nurturing of their relatives and by stepping in to give assistance when older adults need it. With the exception of spouses, most other family members are not chosen, so their characteristics and needs are beyond the control of older adults and can affect the experience of aging. As indicated by the examples in the previous discussion, some of the typical family events that occur in old age - such as disabling illness, retirement taken more to match the spouse's timing than because of one's own preference, or the sudden responsibility to parent one's grandchildren - an insert serious challenges to aging well into an older person's life. Gender, marital status, racial and ethnic background, and health are among the important determinants of the nature of family relationships and activities, which in turn can affect the likelihood of aging well. We continue this discussion in more detail below.

\section{RELATIONSHIPS AS RESOURCES FOR AGING WELL}

To age well, older adults need to develop relationships with people who help them in ways they need and want to be helped. Sometimes feeling dependent is worse for older adults' subjective reaction to aging than receiving no help. The notion of aging well implies that older adults must actively shape their relationships with relatives and friends rather than passively hope that their needs to help and be helped will be met.

Friends and family members can serve as resources for older adults in two ways - by helping them with their instrumental needs and by providing emotional support. Personal relationships are a source of pleasure and companionship and can buffer stress. Friends and family also help elderly adults accomplish the activities of daily living, do household chores, and sometimes even meet financial obligations. Directly, in the case of emotional support, and indirectly, in the case of instrumental support, friends and family members enhance older adults' psychological wellbeing. Some scant evidence suggests that personal relationships might also affect health and longevity (e.g., Bryant \& Rakowski, 1992; Ferraro, Mutran, \& Barresi, 1984), but this possibility needs further investigation. In this section, first we discuss the instrumental support that friends and family members often provide older adults. Then we address the ways in which personal 
relationships provide emotional support to older adults and enhance their psychological wellbeing.

\section{INSTRUMENTAL SUPPORT}

Friends. In general, research shows that family members are more likely to provide elderly adults with instrumental support than friends are. Although it is clear that this finding is accurate, it is possible that the help provided by friends is underestimated in the literature (Adams, 1986a). Most researchers ask hypothetical questions about who would or should help an elderly person with specific tasks when help is needed, or they limit the respondent to naming one care provider. In American society, most people expect that family members, particularly their children, will help older adults (Hamon \& Blieszner, 1990). In contrast, most people see friendship as a voluntary relationship largely without obligations to care for people as they age (Allan, 1986; Litwak, 1985, 1989). It is possible that respondents have given normative responses to hypothetical questions about sources of support rather than accurate reports of what they would actually do or receive if faced with a need for help. When respondents are allowed to name only a primary caregiver, the help given by a loyal friend who provides much, but not the most, assistance remains unnoticed. In two studies (Adams, 1986b, 1987b), when respondents were asked about actual help and were allowed to name all caregivers, elderly people claimed to have received higher rates of assistance from friends than are typically reported.

Friends are more likely to provide support in some circumstances than in others. When elderly people have no family (Cantor \& Johnson, 1978), when they need help from someone experienced in matters of aging (Litwak, 1985), when they need short-term assistance (Litwak, 1985), when it is convenient for a friend to help, when the need for help is unpredictable, or when the older adult has no easy alternative (Adams, 1983), friends respond with the needed aid. Friends are often better equipped to help older adults with bereavement than family members are, because they are more likely to have experienced death of loved ones. Friends often provide older adults with transportation (particularly when they can do so conveniently, in an emergency, or when no one else is available to drive), and they help with home repairs, in times of sickness, with shopping or running errands, and with housekeeping tasks (Adams, 1983).

Relatives. In contrast, family members are more likely than friends to provide assistance to older adults when their needs are significant and chronic (Antonucci \& Akiyama, 1995; Litwak, 1985). Indeed, older adults express a preference for support from kin over friends and neighbors (Travis, 1995). Depending on the functional ability and needs of the elder members, families provide assistance with everyday personal care (bathing, dressing, eating), household tasks (cooking, cleaning, laundry, financial affairs), transportation (especially when needed on an ongoing basis), companionship (leisure activities), and managing contacts with formal sources of support (health care providers, government agency representatives).

Depending on the situation in which older adults find themselves, friends or family members may be more appropriate sources of instrumental support. No doubt, these instrumental forms of assistance from friends and family members are valuable to older adults and indirectly benefit their morale. But in addition, it is important to recognize the more direct contributions that friends and relatives make to older adults' psychological well-being.

EMOTIONAL SUPPORT AND PSYCHOLOGICAL WELL-BEING 
Friends. For almost 2 decades, researchers have accepted the notion that friends are more important to the psychological well-being of older adults than family members are (Antonucci \& Akiyama, 1995; Larson, 1978). Explanations for this well-established finding include the greater importance of achieved (friendship) versus ascribed (family) relationships for mental health, the greater likelihood of older people confiding in age-peers (which friends tend to be), and the greater tendency of friends to involve older people with the larger society (Chappell, 1983; Litwak, 1985).

The causal direction of the relationship between friendship and psychological well-being is not clear. Most researchers have assumed that it is unidirectional, with a change in friendship activity leading to a change in psychological well-being (see Matt \& Dean, 1993). The results of at least one study, though, suggest that the relationship is nonrecursive: When older people feel badly, they seek out new friends; when they are separated from old friends, they do not feel as good (Adams, 1988). In any case, research shows a strong connection between friendship quality and psychological well-being. For example, perceived adequacy of interactions with friends, in terms of the amount and meaning of the interaction and the level of satisfaction with it, are significant predictors of happiness (Baldassare, Rosenfield, \& Rook, 1984; Gibson, 1986-1987).

Relatives. Although friend relationships are generally more crucial for an elderly person's psychological well-being, family relationships also affect happiness. For example, taking an intragenerational focus, married women's well-being is strongly influenced by their husbands' perceptions of the marriage, well-being, and physical health, although husbands' well-being apparently is not affected by characteristics of their wives (Quirouette \& Pushkar-Gold, 1992). Feelings of attachment and emotional closeness with siblings, particularly sisters, also contribute to well-being in old age (Bedford, 1995; Cicirelli, 1989).

Looking through an intergenerational lens, research on aging parent-adult child relations shows that the quality of the parent-child relationship, as assessed by variables such as affection and communication, is positively related to parental psychological well-being (Mancini \& Blieszner, 1989). Morale is enhanced when older adults perceive that their adult children would, in fact, respond appropriately should a need for help arise (Blieszner \& Hamon, 1992). Parents are especially likely to rely on their children in widowhood, and the support children provide. eases their grief (Suitor, Pillemer, Keeton, \& Robison, 1995). Grandparenting, too, enhances psychological well-being to the extent that it provides opportunities for older adults to serve as kin keepers in fostering family contact and as fonts of family history (Brubaker, 1990b; Robertson, 1995). In the case of elders who assume primary care responsibility for their grandchildren, however, well-being is diminished if the parenting of grandchildren interferes with their health and social activities (Minkler, Roe, \& Robertson-Beckley, 1994).

\section{CONCLUSION}

Although more research is needed on the importance of choices regarding friendship and family relationships for how well people age, clearly such relationships are salient. The question remains, however, whether policy makers and program designers should plan, support, and finance interventions into the personal relationships of older adults. Democrats might argue that support of programs enhancing personal relationships is warranted if such programs aid people in aging well. Republicans might contend that society cannot afford to intervene in such matters, 
even if the programs would help. Libertarians might maintain that personal relationships are private matters and any intervention, no matter how helpful, would be intrusive and a violation of civil liberties.

Political debate on what action to take is in some senses moot, because policies and programs that are already in place subject personal relationships to manipulation on a regular basis. Existing legislation more commonly is designed to affect family relationships than friendships. Defining who belongs in the category relative is much easier than defining who belongs in the category friend. For this reason, programs affecting family relationships are much less expensive than programs involving friends would be (see Mayhew, 1970, for a general discussion of why policy is most often based on ascribed rather than on achieved characteristics). Examples of policies that have direct or indirect effects on the family relationships of older adults are the Social Security Act (including retirement, disability, and survivors income; Supplemental Security Income; Medicare; and Medicaid), the Food Stamp Act, the Older Americans Act, the Age Discrimination in Employment Act, the Housing and Community Development Act, and the Family Leave Bill (see Harrington Meyer \& Bellas, 1995, for a detailed discussion of the implications of old age-related policies for family relationships). Community programs and services are also available to help aged persons achieve their goals for aging well and to aid families caring for their elders. Examples include family counseling agencies, support groups, and respite programs (Gatz, Bengtson, \& Blum, 1990).

Although federal lawmakers have not passed legislation intentionally designed to affect older adults' friendships, many programs, some subsidized by tax dollars, do shape them. For example, social workers organize nutrition centers at which older adults make new acquaintances. Therapists encourage widows and other older adults to develop interpersonal skills. Architects design age-segregated housing projects to enhance social interaction among the residents. Consultants advise companies on how to help retirees maintain active social lives after departing from their life-long jobs. Planners design multilevel care communities to allow for the continuity of social lives.

These personal relationship interventions occur at the level of the society, community, immediate social environment, network, dyad, or individual. (Adams \& Blieszner, 1993). The more remote the level of intervention is from the individual, the larger the number of people who are affected and the less noticeable the effect is on a particular person's personal relationships. Similarly, the more remote the level of intervention, the less likely the intervention is to be consciously planned and the less likely the consequences are to be carefully noted.

Elsewhere (Adams \& Blieszner, 1993) we argued that interventions into personal relationships should be responsibly designed rather than taking place as a consequence of policies or programs developed for some other purpose. Moreover, if such interventions take place, they should be informed by relevant research findings. Because each person ages well differently, interventions should take into account the need to tailor program goals to the situation facing each individual, rather than setting similar goals for all program participants. The consequences should be carefully monitored and evaluated so that experiences can be shared and interventions can be improved or terminated over time (Adams \& Blieszner, 1993). An important example of the complexities of designing relationship interventions is provided in the discussion of a program 
that did not accomplish the intended outcomes (Heller, Thompson, Trueba, Hogg, \& VlachosWeber, 1991; Heller, Thompson, Vlachos-Weber, Steffen, \& Trueba, 1991). Older adults' personal relationships are not totally within their own control. If policy makers and program planners intervene into the social lives of older adults, they must do so consciously and carefully rather than unintentionally and haphazardly. Such well-informed efforts might then be able to help older adults make effective relationship choices in their pursuit of aging well.

\section{REFERENCES}

Adams, R. G. (1983). Friendship and its role in the lives of elderly women. Unpublished doctoral dissertation, University of Chicago.

Adams, R. B. (1985). People would talk: Normative barriers to cross-sex friendship for elderly women. The Gerontologist, 25, 605-611.

Adams, R. G. (1986a). Friendship and aging. Generations, 10, 40-43.

Adams, R. G. (1986b). The Davidson County study on aging, part II: Needs now and in the future (Technical Report). University of North Carolina at Greensboro, Center for Social Research and Human Services.

Adams, R. G. (1987a). Patterns of network change: A longitudinal study of friendships of elderly women. The Gerontologist, 27, 222-227.

Adams, R. G. (1987b). The Yadkin County study on aging: Current and future needs (Technical

Report). University of North Carolina at Greensboro, Center for Social Research and Human Sciences.

Adams, R. G. (1988). Which comes first: Poor psychological well-being or decreased friendship activity? Activities, Adaptation, and Aging, 12, 27-41.

Adams, R. G. (1989). Conceptual and methodological issues in studying friendships of older adults. In R. G. Adams \& R. Blieszner (Eds.), Older adult friendship: Structure and process (pp. 17-41). Newbury Park, CA: Sage.

Adams, R. G., \& Blieszner, R. (Eds.). (1989). Older adult friendship: Structure and process. Newbury Park, CA: Sage.

Adams, R. G., \& Blieszner, R. (1993). Resources for friendship intervention. Journal of Sociology and Social Welfare, 20(4), 159-175.

Adams, R. G., \& Blieszner, R. (1994). An integrative conceptual framework for friendship research. Journal of Social and Personal Relationships, 11, 163-184.

Albert, S. M., \& Moss, M. (1990). Consensus and the domain of personal relations among older adults. Journal of Social and Personal Relationships, 7, 353-369.

Allan, G. A. (1986). Friendship and care for elderly people. Ageing and Society, 6, 1-12.

Allan, G. A. (1989). Friendship: Developing a sociological perspective. Hertfordshire, UK: Harvester Wheatsheaf.

Antonucci, T. C., \& Akiyama, H. (1995). Convoys of social relations: Family and friendships within a life span context. In R. Blieszner \& V. H. Bedford (Eds.), Handbook of aging and the family (pp. 355-371). Westport, CT: Greenwood.

Atchley, R. C. (1994). Social forces and aging (7th ed.). Belmont, CA: Wadsworth.

Babchuk, N., \& Anderson, T. B. (1989). Older widows and married women: Their intimates and confidants. International Journal of Aging and Human Development, 28, 21-35.

Baldassare, M., Rosenfield, S., \& Rook, K. (1984). The types of social relations predicting elderly well-being. Research on Aging, 6, 549-559. 
Bear, M. (1990). Social network characteristics and the duration of primary relationships after entry into long-term care. Journal of Gerontology: Social Sciences, 45, S156-S162.

Bedford, V. H. (1995). Sibling relationships in middle and old age. In R. Blieszner \& V. H. Bedford (Eds.), Handbook of aging and the family (pp. 201-222). Westport, CT: Greenwood. Bengtson, V. L., \& Achenbaum, W. A. (Eds.). (1993). The changing contract across generations. Hawthorne, NY: Aldine.

Bengtson, V. L., Rosenthal, C., \& Burton, L. (1990). Families and aging: Diversity and heterogeneity. In R. H. Binstock \& L. K. George (Eds.), Handbook of aging and the social sciences (3rd ed., pp. 263-287). San Diego: Academic Press.

Blieszner, R. (1993). Resource exchange in the social networks of elderly women. In U. G. Foa, J. Converse, Jr., K. Y. Tornblom, \& E. B. Foa (Eds.), Resource theory: Explorations and applications (pp. 76-79). San Diego: Academic Press.

Blieszner, R., \& Adams, R. G. (1992). Adult friendship. Newbury Park, CA: Sage.

Blieszner, R., \& Bedford, V. H. (1995a). The family context of aging: Trends and challenges. In R. Blieszner \& V. H. Bedford (Eds.), Handbook of aging and the family (pp. 3-12). Westport, CT: Greenwood.

Blieszner, R., \& Bedford, V. H. (Eds.). (1995b). Handbook of aging and the family. Westport, CT: Greenwood.

Blieszner, R., \& Hamon, R. K. (1992). Filial responsibility: Attitudes, motivators, and behaviors. In J. W. Dwyer \& R. T. Coward (Eds.), Gender, families, and elder care (pp. 105-119). Newbury Park, CA: Sage.

Brubaker, T. H. (Ed.). (1990a). Family relationships in later life (2nd ed.). Newbury Park, CA:

Sage.

Brubaker, T. H. (1990b). Families in later life: A burgeoning research area. Journal of Marriage and the Family, 52, 959-981.

Bryant, S., \& Rakowski, W. (1992). Predictors of mortality among elder African-Americans. Research on Aging, 14, 50-67.

Cantor, M., \& Johnson, J. (1978, November). The informal support systems of the family-less elderly - Who takes over? Paper presented at the 31st Annual Scientific Meeting of the Gerontological Society of America, Dallas.

Cavanaugh, J. C. (1993). Adult development and aging (2nd ed.). Monterey, CA: Brooks-Cole. Chappell, N. (1983). Informal support networks among the elderly. Research on Aging, 5, 77-99. Cicirelli, V. G. (1989). Feelings of attachment to siblings and well-being in later life. Psychology and Aging, 4, 211-216.

Connidis, I. A., \& Davies, L. (1990). Confidants and companions in later life. Journal of Gerontology: Social Sciences, 45, S141-S149.

Coward, R. T., Horne, C., \& Dwyer, J. W. (1992). Demographic perspectives on gender and family caregiving. In J. W. Dwyer \& R. T. Coward (Eds.), Gender, families, and elder care (pp. 18-33). Newbury Park, CA: Sage.

Dykstra, P. (1990). Next of (non)kin. Amsterdam: Swets \& Zeitlinger.

Ferraro, K. F., Mutran, E., \& Barresi, C. M. (1984). Widowhood, health and friendship support in later life. Journal of Health and Social Behavior, 25, 245-259.

Field, D., Minkler, M., Falk, R. F., \& Leino, E. V. (1993). The influence of health on family contacts and family feelings in advanced old age: A longitudinal study. Journal of Gerontology: Psychological Sciences, 48, P18-P28. 
Fischer, C. S., \& Oliker, S. J. (1983). A research note on friendship, gender, and the life cycle. Social Forces, 62, 124-133.

Fisher, C. B., Reid, J. D., \& Melendez, M. (1989). Conflict in families and friendships in later life. Family Relations, 38, 83-89.

Gatz, M., Bengtson, V. L., \& Blum, M. J. (1990). Caregiving families. In J. E. Birren \& K. W. Schaie (Eds.), Handbook of the psychology of aging (3rd ed., pp. 404-426). San Diego:

Academic Press.

Gibson, D. M. (1986-1987). Interaction and well-being in old age: Is it quantity or quality that counts? International Journal of Aging and Human Development, 24, 29-40.

Hamon, R. R., \& Blieszner, R. (1990). Filial responsibility expectations among adult child-older parent pairs. Journal of Gerontology: Psychological Sciences, 45, P110-P112.

Hansson, R. O., Jones, W. H., \& Fletcher, W. L. (1990). Troubled relationships in later life: Implications for support. Journal of Social and Personal Relationships, 7, 451-463.

Harrington Meyer, M., \& Bellas, M. L. (1995). U.S. old age policy and the family. In R.

Blieszner \& V. H. Bedford (Eds.), Handbook of aging and the family (pp. 263-283). Westport, CT: Greenwood.

Hatch, L. R., \& Bulcroft, K. (1992). Contact with friends in later life: Disentangling the effects of gender and marital status. Journal of Marriage and the Family, 54, 222-232.

Heller, K., Thompson, M. G., Trueba, P. E., Hogg, J. R., \& Vlachos-Weber, I. (1991). Peer support telephone dyads for elderly women: Was this the wrong intervention? American Journal of Community Psychology, 19, 53-74.

Heller, K., Thompson, M. G., Vlachos-Weber, I., Steffen, A.M., \& Trueba, P. E. (1991). Support interventions for older adults: Confidante relationships, perceived family support, and meaningful role activity. American Journal of Community Psychology, 19, 139-146.

Himes, C. L. (1992). Future caregivers: Projected family structures of older persons. Journal of Gerontology: Social Sciences, 47, S17-S26.

Huyck, M. H. (1995). Marriage and close relationships of the marital kind. In R. Blieszner \& V. H. Bedford (Eds.), Handbook of aging and the family (pp. 181-200). Westport, CT: Greenwood. Johnson, C. L. (1995). Cultural diversity in the late-life family. In R. Blieszner \& V. H. Bedford (Eds.), Handbook of aging and the family (pp. 307-331). Westport, CT: Greenwood.

Johnson, C. L., \& Troll, L. E. (1994). Constraints and facilitators to friendships in later life. The Gerontologist, 34, 79-87.

Jones, D.C., \& Vaughan, K. (1990). Close friendships among senior adults. Psychology and Aging, 5, 451-457.

Kinsella, K. (1995). Aging and the family: Present and future demographic issues. In R.

Blieszner \& V. H. Bedford (Eds.), Handbook of aging and the family (pp. 32-56). Westport, CT: Greenwood.

Lang, F. R., \& Carstensen, L. L. (1994). Close emotional relationships in late life: Further support for proactive aging in the social domain. Psychology and Aging, 9, 315-324.

Larson, R. (1978). Thirty years of research on the subjective well-being of older Americans. Journal of Gerontology, 33, 109-125.

Litwak, E. (1985). Helping the elderly. New York: Guilford.

Litwak, E. (1989). Forms of friendship among older people in an industrial society. In R. G.

Adams \& R. Blieszner (Eds.), Older adult friendship: Structure and process (pp. 65-88).

Newbury Park, CA: Sage. 
Mancini, J. A., \& Blieszner, R. (1989). Aging parents and adult children: Research themes in intergenerational relations. Journal of Marriage and the Family, 51, 275-290.

Manheimer, R. J. (1995). The second middle age. Detroit: Visible Ink.

Matt, G. E., \& Dean, A. (1993). Social support from friends and psychological distress among elderly persons: Moderators effects of age. Journal of Health and Social Behavior, 34, 187-200.

Matthews, S. H. (1983). Definitions of friendship and their consequences in old age. Ageing and Society, 3, 141-155.

Mayhew, L. (1970). Ascription in modern society. In E. O. Laumann, P.M. Siegel, \& R. W. Hodge (Eds.), The logic of social hierarchies (pp. 308-323). Chicago: Markham.

Minkler, M., Roe, K. M., \& Robertson-Beckley, R. J. (1994). Raising grandchildren from crackcocaine households: Effects on family and friendship ties of African-American women.

American Journal of Orthopsychiatry, 64, 20-29.

O'Connor, P. (1992). Friendships between women: A critical review. New York: Guilford.

Quirouette, C., \& Pushkar-Gold, D. (1992). Spousal characteristics as predictors of well-being in older couples. International Journal of Aging and Human Development, 34, 257-269.

Rawlins, W. K. (1992). Friendship matters: Communication, dialectics, and the life course. Hawthorne, NY: Aldine.

Retsinas, J., \& Garrity, P. (1985). Nursing home friendships. The Gerontologist, 25, 376-381. Robertson, J. (1995). Grandparenting in an era of rapid change. In R. Blieszner \& V. H. Bedford (Eds.), Handbook of aging and the family (pp. 243-260). Westport, CT: Greenwood.

Rook, K. S. (1984). The negative side of social interaction: Impact on psychological well-being. Journal of Personality and Social Psychology, 46, 1097-1108.

Rook, K. S. (1987). Reciprocity of social exchange and social satisfaction among older women. Journal of Personality and Social Psychology, 52, 145-154.

Rook, K. S. (1989). Strains in older adults' friendships. In R. G. Adams \& R. Blieszner (Eds.), Older adult friendship: Structure and process (pp. 166-194). Newbury Park, CA: Sage.

Ryff, C. D., Schmutte, P.S., \& Lee, Y. H. (in press). How children turn out: Implications for parental self-evaluation. In C. D. Ryff \& M. M. Seltzer (Eds.), The parental experience in midlife. Chicago: University of Chicago Press.

Shea, L., Thompson, L., \& Blieszner, R. (1988). Resources in older adults' old and new friendships. Journal of Social and Personal Relationships, 5, 83-96.

Spakes, P. R. (1979). Family, friendship and community interaction as related to life satisfaction of the elderly. Journal of Gerontological Social Work, 1, 279-293.

Suitor, J. J., Pillemer, K., Keeton, S., \& Robison, J. (1995). Aged parents and aging children:

Determinants of relationship quality. In R. Blieszner \& V. H. Bedford (Eds.), Handbook of aging and the family (pp. 223-242). Westport, CT: Greenwood.

Szinovacz, M., \& Ekerdt, D. J. (1995). Families and retirement. In R. Blieszner \& V. H. Bedford (Eds.), Handbook of aging and the family (pp. 375-400). Westport, CT: Greenwood.

Travis, S. S. (1995). Families and formal networks. In R. Blieszner \& V. H. Bedford (Eds.), Handbook of aging and the family (pp. 459-473). Westport, CT: Greenwood.

U.S. Bureau of the Census. (1990). Marital status and living arrangements: March, 1989. Current Population Reports (Series P-20, No. 445). Washington, DC: U.S. Government Printing Office. Usui, W. M. (1984). Homogeneity of friendship networks of elderly Blacks and Whites. Journal of Gerontology, 39, 350-356. 
Webster, P. S., \& Herzog, A. R. (1995). Effects of parental divorce and memories of family problems on relationships between adult children and their parents. Journal of Gerontology: Social Sciences, 50B, S24-S34.

Weiss, L., \& Lowenthal, M. F. (1975). Life-course perspectives on friendship. In M. F. Lowenthal, M. Thurnher, D. Chiriboga, \& Associates (Eds.), Four stages of life (pp. 48-61). San Francisco: Jossey-Bass.

Worobey, J. L., \& Angel, R. J. (1990). Functional capacity and living arrangements of unmarried elderly persons. Journal of Gerontology: Social Sciences, 45, S95-S101. 